\title{
Kinematic Analysis of Handwriting Movements in Individuals with Intellectual Disabilities with and without Obsessive Compulsive Symptoms
}

\author{
Oliver Schabos Knut Hoffmann Björn Enzi Georg Juckel \\ Paraskevi Mavrogiorgou \\ Department of Psychiatry, Ruhr University Bochum, LWL University Hospital, Bochum, Germany
}

\section{Keywords \\ Intellectual disabilities - Obsessive-compulsive disorder . \\ Movement disorder · Stereotypies · Kinematic analysis}

\begin{abstract}
Theory/calculation: Movement disorders such as disturbances of coordination, clumsiness, and hand-related stereotypies are a frequent phenomenon in individuals with intellectual disabilities (ID). Obsessive-compulsive symptoms are also common in persons with ID. Our aim was to investigate hand motor dysfunction in persons with ID with and without $O C D$, using a digitizing tablet and the kinematic analysis of handwriting and drawing movements. Methods: We examined the hand motor performance of 23 individuals (12 males, 11 females, $42.6 \pm 13.7$ years old) with ID of heterogeneous aetiology. All subjects were required to write a sentence and draw circles under various conditions. Kinematic parameters were calculated to quantify hand motion. Results: Individuals with ID exhibit serious hand motor impairments suggestive of bradykinesia, irregularity, and micrographia. More than half of our ID patients $(60.9 \%)$ displayed obsessive-compulsive symptoms of moderate severity (Y-BOCS total score: $16.6 \pm 8.3$ ). Interestingly, the ID patients with OCD displayed smaller amplitudes of hand
\end{abstract}

motor movements than did patients with no obsessive-compulsive symptoms, while differences observed in the writing and drawing concentric circles trials were significant. Conclusions: The results of this pilot study support the use of kinematic analyses of handwriting movements to evaluate motor abnormalities in patients with ID and comorbid mental illnesses.

(c) 2020 S. Karger AG, Basel

\section{Introduction}

The term "motor activities" is understood as encompassing all active movements that are coordinated and controlled by the brain. However, motor activity is a complex process of action influenced by many factors, such as emotion, motivation, cognition, and sensory perception, leading to movement. Thus, motor activity should in fact be thought of as "psychomotor activity," i.e. a combination of somatic-motor and psycho-cognitive sub-processes.

Furthermore, the term "movement disorders" is used generally to encapsulate all abnormal arbitrary and/or voluntary movements that are a result of dysfunction of the CNS or neuromuscular system. Studies of movement

\section{KARGER}

(c) 2020 S. Karger AG, Basel

karger@karger.com

www.karger.com/psp
Prof. Dr. med. Georg Juckel, MD, PhD

Department of Psychiatry, Ruhr University Bochum, LWL University Hospital Alexandrinenstrasse 1

DE-44791 Bochum (Germany)

E-Mail JuckelGWK@aol.com 
disorders in adults with intellectual disabilities (ID) are rare, despite a range of neurodevelopmental disorders and genetic syndromes associated with more or less pronounced deficits of motor skills and movement.

ID affects approximately $1-3 \%$ of the world's population [1]. Movement disorders such as disturbances of coordination, clumsiness, balance instability, tics, dystonia, and hand-related stereotypies are common conditions in individuals with various neurodevelopmental diseases, including specific genetic syndromes as well as idiopathic intellectual and developmental disability. However, in up to $40 \%$ of individuals with ID, no pathogenetic causes can be verified; in only $5 \%$ of cases is it accompanied by a genetic syndrome such as Down syndrome, Angelman syndrome, Rett syndrome, or Prader-Willi syndrome [2].

Conversely, there is extreme heterogeneity of abnormal movement across genetic syndromes. Thus, in Angelman syndrome, movement disorders are nearly universal, most frequently presenting as ataxia and tremor [3], while the movements of persons with Down syndrome are described in the sense of clumsiness in association with their overall slowness and speeding up with their movements [4].

In summary, it is estimated that in about $50 \%$ of individuals with ID, various kinds of abnormal movements are present, and that in $25 \%$ these movement disorders are severe. The most common movement disorders among people with ID are motor stereotypies, chewing movements, tremor, and body rocking, as well as selfharming behaviour such as self-biting, head banging, or self-scratching $[5,6]$.

Furthermore, hand-related stereotypies (i.e., hand-/ finger-mouthing, eye poking) form a large part of the overall stereotypy range and can thus be considered largely illustrative of both the problem and available intervention strategies [7]. Ultimately, all involuntary postural and movement disorders related to dysfunction of the extrapyramidal motor system (ataxia, athetosis, ballism, bradylalia, chorea, myoclonus, parkinsonism, tremor) can occur in persons with ID [7].

Unfortunately, psychiatric comorbidities such as depressive or anxiety disorders are also frequent at high rates among patients with ID $[8,9]$. Obsessive-compulsive symptoms are common too in people with ID, with a prevalence rate of at least 3.5\% [10]. Therefore, difficulties in detecting and diagnosing OCD in adults with ID consist of problems in distinguishing compulsions from stereotypies and other repetitive behaviours. However, persons with ID often have difficulty describing their OCD symptoms as senseless and ego-dystonic.

Handwriting in ID with and without OCD
Certainly here, the correct diagnosis of different movement disorders and behavioural psychomotor problems can be difficult, because for most of these disorders no specific biological markers are available. Moreover, the diagnostic meaningfulness of many available tests, which are often time-consuming and expensive, is limited for several reasons, e.g. non-specificity, due to the meaning of some authors [11]. On the other hand, many individuals with ID also have deficits in basic knowledge and communication skills, as well as limited opportunity for autonomous decision-making, making it difficult for them to participate in trials. As a result, there have been only a few studies of the kinematics of body and hand movements in individuals with ID. In one of these [12], significant improvement in the quality of letter writing was found in 6 severely mentally retarded adults following the introduction of computerised handwriting instructions.

It must be noted that most of the findings of these few studies are limited by several factors, such as small sample size, patient use of different medication, the heterogeneity of the study population, and the conventional methods available. In comparison with these conventional investigations of motor performance (using motor tests or rating scales), the recording of hand movements while writing and drawing using a digitizing graphic tablet, along with computer-aided analysis of these movements, is a simple, non-invasive method for the precise and objective measurement of hand movement disorders. Several studies have demonstrated its value in objectively measuring hand motor performance in healthy subjects [13] and patients with various neuropsychiatric disorders such as dementia [14], depression [15-17], schizophrenia $[18,19]$, and OCD $[15,20]$.

To our knowledge, investigations using a digitizing graphic tablet and computer-aided analysis of hand movements of patients with ID currently do not exist. Accordingly, the primary aim of the present pilot study was to examine the motor performance of patients with ID with and without psychiatric comorbidity and challenging behaviour, using a digitalising graphic tablet. The second aim was to investigate the differential impact of additionally having or not having obsessive-compulsive symptoms, as well as psychomotor behaviour problems such as stereotypies, on the basis of measurement scales and digitised analyses of movement in patients with ID. Thus, examining motor performance in ID with and without OCD by an objective tool could improve the diagnostic process. 
Fig. 1. Procedure of kinematic analysis of handwriting movements using digitising graphic table.

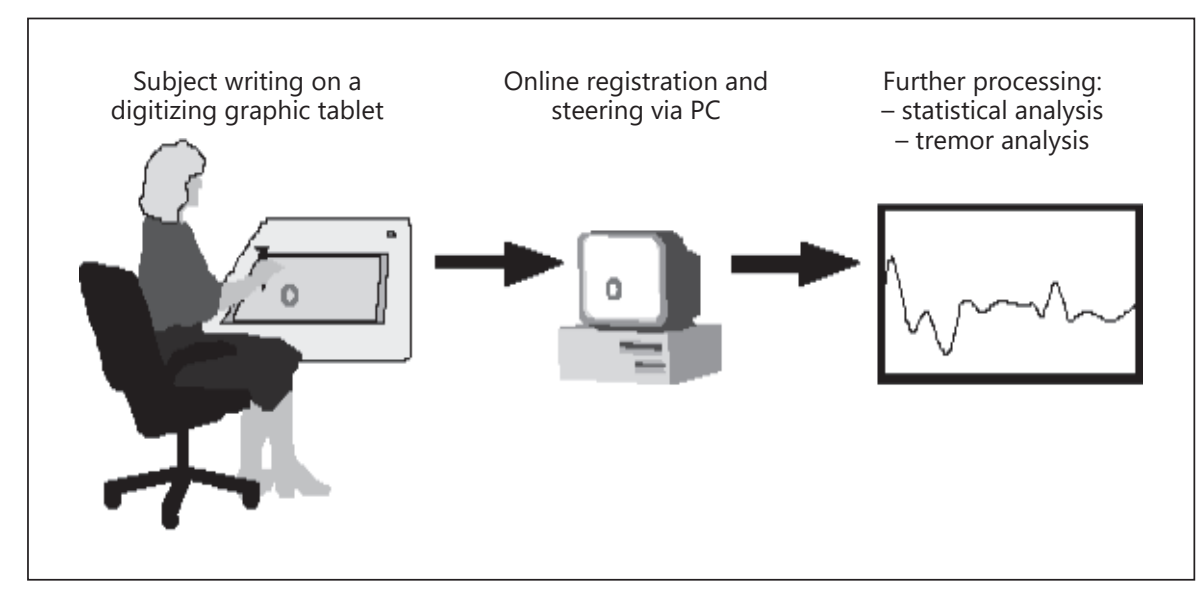

\section{Methods and Materials}

\section{Subjects}

Twenty-three individuals with ID ( $11=$ female, $12=$ male, mean age $42.6 \pm 13.7$ years), who met the criteria for ID based on the Research Diagnostic Criteria of the International Classification of Disorders (ICD-10: F70-F72; [21]), participated in the study. They were recruited from the outpatient clinic for Developmental Disability at the Department of Psychiatry, Ruhr-University Bochum, Germany.

All subjects gave written informed consent after the study was fully explained to them. In patients with limited legal capacity, consent was obtained from their legal representatives or caregivers after they had been given a detailed study description and explanation. In accordance with the Helsinki Declaration of 1975, the study was approved by the local university ethics committee of Ruhr University Bochum, Germany.

Exclusion criteria were the following: severe somatic diseases, acute psychotic disorders, acute suicidality, and failed informed consent by patients or caregiver.

All participants (22 right-handed, 1 left-handed) underwent various psychometric tests, including for depressive symptoms, Hamilton Depression Scale (HAMD-21 [22]), and for obsessivecompulsive symptoms, the Y-BOCS and Y-BOCS-Symptom Checklist $[23,24]$. Participants' verbal intelligence was assessed using the Mehrfachwahlwortschatztest (MWT-IQ [25]). Non-verbal IQ was investigated before in order to diagnose the patients correctly. The overall severity of their psychiatric disorder was measured using the Clinical Global Impression (CGI) score (NIMH [26]).

Psychosocial functioning was measured by the Personal and Social Performance Scale (PSP). This scale allows a more exact and specific operationalisation of patients' occupational, social, and personal functioning domains $[27,28]$.

In order to assess their maladaptive behaviours, participants completed the following rating instruments:

The Aberrant Behavior Checklist (ABC [29]) is a reliable and valid behaviour-rating instrument for use with individuals with ID with 5 subscales: I (Irritability), II (Lethargy), III (Stereotypy), IV (Hyperactivity), and V (Inappropriate speech). In addition, a total score can be calculated.
The Behaviour Problems Inventory-Short (BPI-S; [30, 31]) was used to assess the maladaptive behaviours of individuals with ID. The BPI-S is an observer-based, behaviour-rating instrument with 30 items across three subscales: Self-injurious behaviour ( 8 items); Aggressive/destructive behaviour (10 items); and Stereotyped behaviour (12 items).

The Stereotypy Severity Scale (SS-Scale [32]) was modified from the Yale Global Tic Severity Scale [33] and constructed to measure stereotypic movements rather than tics. The SS-Scale consists of two components: one pertaining to the motor dimensions of a movement, the other to the global effects of a movement.

To validate the nature and severity of catatonic symptoms, we used the Catatonia Rating Scale (CRS [34]).

The Scheme of Emotional Development (SEO [35, 36]) was used to assess the level of emotional development (ED) of participants. The SEO is a semi-structured interview that evaluates the developmental level reached in 10 basic aspects of ED.

The Pervasive Developmental Disorder Mentally Retardation Scale (PDD-MRS [37]) is a simple classification and screening instrument for identifying autistic spectrum disorders in individuals with ID. In this study, we used the German version, called SEAS-M (Skala zur Erfassung von Autismusspekrumstörungen bei Minderbegabten [37]).

Eleven of the participants were on medication at the time of assessment, 7 of whom were taking more than two psychotropic substances (antidepressants plus antipsychotics and mood stabilisation medication) and 4 of whom were taking only one substance.

\section{Apparatus and Procedure}

A digitizing graphic tablet (WACOM IV), with a sampling rate of maximally $200 \mathrm{~Hz}$ and a spatial resolution of $0.05 \mathrm{~mm}$, was used to record the $x-y$ co-ordinates of subjects' hand movements. The tablet was connected to a personal computer (laptop) (Fig. 1).

Control of the trials, data recording, and subsequent signal processing were carried out using a commercially available programme (CSWin, version 2012 [38]).

All subjects were asked to write and draw using a special ballpoint pen with magnetic sensors. They received visual feedback on their hand movements while writing and drawing. All sessions were video-taped; attention and performance were controlled in analyses of this material afterwards. First, subjects were asked to 

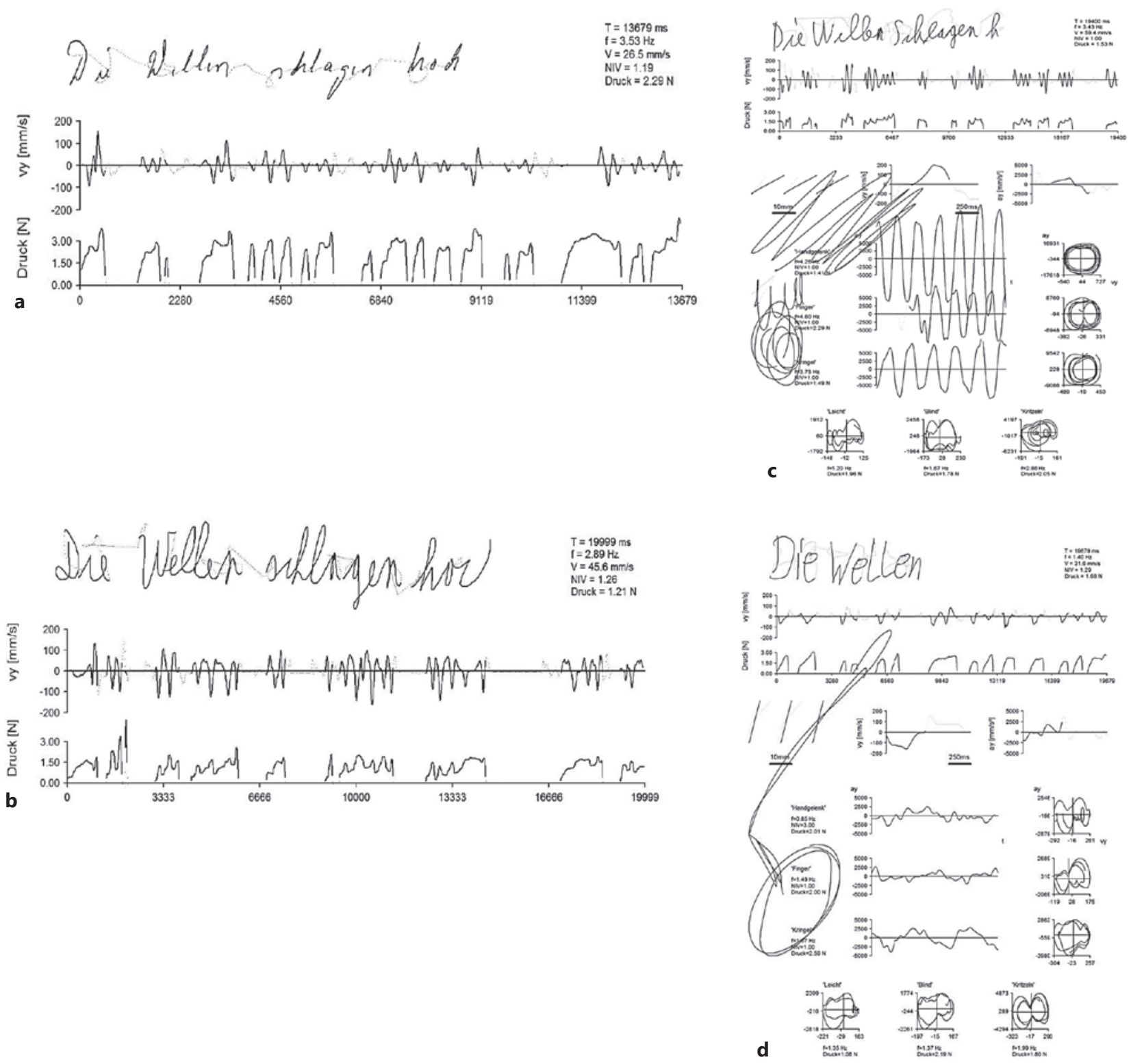

Fig. 2. Write performance profile. a 49-year-old female patient with mild intellectual disability and comorbid obsessive-compulsive disorder. b 51-year-old male patient with ID and autism. c 63-year-old male patient with ID and stereotypies. d 59-year-old female patient with ID and without OC symptoms.

write with their dominant hand the sentence: "Die Wellen schlagen hoch" ("the waves hit high") on a sheet of white paper. They were instructed to write not as neatly or quickly as possible but as they do normally, in a natural writing position (Fig. 2). They were then asked to write, again with the dominant hand, the letter sequence "III" in a row, using cursive handwriting and without lifting the ballpoint pen off the paper. This task was repeated under various conditions, e.g. fast movements performed from the wrist or the fingers. The next task was to draw concentric, superimposed circles, again under various conditions (e.g., faster, less pressure on the pen, with eyes closed). After all that, subjects were asked to draw a pointless scribble on a spot on a sheet of white paper.

\section{Kinematic Data Analysis}

The velocity and acceleration curves for handwriting were computed for the $x$ and $y$ coordinates. In CSWin, non-parametric kernel estimation was applied to calculate and smooth the velocity and acceleration profiles [39]. To determine the different quantita- 
tive variables of motion, the co-ordinates of handwriting movements and their first and second derivations (velocity and acceleration) were divided into time segments called strokes. Strokes are defined as the distance between two sequential extreme scores (maxima and minima) for the two co-ordinates [13, 40]. Since the ascending and descending strokes were of particular relevance, the movement analysis focused on the $y$ coordinates.

Using automatic algorithms for each subject and each trial, the following kinematic parameters were calculated using CSWin: the arithmetic mean of frequency (in $\mathrm{Hz}$ ); the arithmetic mean of stroke duration (in ms); the arithmetical mean of stroke length (in $\mathrm{mm}$ ); and the variation coefficient of stroke peak velocity (in \%). All these parameters reflect independent aspects of the dynamics of hand movements, allowing precise conclusions to be drawn regarding the quality of the handwriting process. Average stroke duration provides an accurate measure of bradykinesia [18], while average stroke length reflects the level of micrographia. In order to determine the automatisation of movement processes, the NIV (number of inversions of velocity) parameter was used. Mean writing pressure (in newtons) was also measured.

\section{Statistical Analysis}

All the results of the kinematic analysis were imported into the statistical programme IBM SPSS Statistics for Windows, Version 23.0 (IBM Corp., Armonk, NY, USA). Further statistical analyses of the neuropsychological, behavioural, and kinematic data were performed. Descriptive statistics are given as mean values, standard deviation, and range. Statistical analyses were performed with appropriate parametric or non-parametric tests ( $t$ test, ANOVA and Pearson or Spearman correlation coefficients). Statistical significance was set at $p<0.05$. A $p$ value $<0.10$ was regarded as statistical tendency.

\section{Results}

\section{Sociodemographic and Clinical Characteristics}

The sociodemographic and clinical characteristics of the 23 patients with ID are summarised in Table 1.

More than half of the ID patients $(n=14 ; 60.9 \%)$ had obsessive-compulsive symptoms of moderate severity (YBOCS Obsessions: $8.5 \pm 4.0$; Y-BOCS Compulsions: $8.1 \pm$ 5.0; Y-BOCS total score: $16.6 \pm 8.3$ ). Based on the Y-BOCS Symptom checklist, the most common categories were contamination obsessions, aggressive obsessions, cleaning compulsions, checking compulsions, and hoarding.

In the 9 patients without additional OCD, the following additional psychiatric diagnoses (according to ICD-10) were made: organic affective disorder $(n=2)$, organic schizophrenic psychosis $(n=1)$, psycho-organic syndrome following early craniocerebral injury $(n=2)$, fragile $\mathrm{X}$ syndrome $(n=1)$, and autism spectrum disorder $(n=3)$.

The severity of depressive symptoms for the whole group according to the HAMD-21 was mild, with a total mean score of $5.4 \pm 4.8$.
Table 1. Sociodemographic and clinical characteristics of the subjects with intellectual disabilities $(n=23)$

\begin{tabular}{ll}
\hline Gender & \\
$\quad$ Female & $11(40.8)$ \\
Male & $12(52.2)$ \\
\hline Age, years & \\
$\quad$ Mean \pm SD & $42.57 \pm 13.65$ \\
$\quad$ Range & $22-63$ \\
\hline Marital status & \\
$\quad$ Married & $3(13)$ \\
$\quad$ Cohabitating & $11(47.8)$ \\
$\quad$ Single & $9(39.1)$ \\
\hline Education & \\
Lower secondary school & \\
$\quad$ (Hauptschule) & $4(17.4)$ \\
$\quad$ Special school (Sonderschule) & $19(82.6)$ \\
\hline Occupational status & \\
No completed vocational training & $23(100)$ \\
Employed in a sheltered workshop & $18(78.3)$ \\
Unemployed & $5(21.7)$ \\
\hline Handedness & \\
Right & $22(95.7)$ \\
Left & $1(4.3)$ \\
\hline Intellectual disability & $17(73.9)$ \\
Low (ICD-10: F70) & $6(26.1)$ \\
Middle (ICD-10: F71) & 0 \\
Severe (ICD-10: F72) & $16.6 \pm 4.8$ \\
\hline YAM-D score & $4.9 \pm 0.67$ \\
CGI & $58.8 \pm 12.0$ \\
PSP & \\
\hline
\end{tabular}

Data are presented as $n(\%)$, mean \pm standard deviation, or as stated. HAM-D, Hamilton-Depression Scale; Y-BOCS, YaleBrown Obsessive-Compulsive Scale; CGI, Clinical Global Impressions; PSP, Personal and Social Performance Scale.

The mean total PSP score was $58.8 \pm 12.0$, indicating marked difficulties in the form of disturbing and aggressive behaviour. Based on the CGI score, illness severity was classified as "markedly ill" (4.9 \pm 0.67$)$.

With regard to aberrant behaviour as measured using the $\mathrm{ABC}$ [29], the highest mean score for the whole sample was found for the hyperactivity subscale $(8.5 \pm 8.1)$. Table 2 displays the mean score for each subscale and the total score for $\mathrm{ABC}$. When looking at the results across those participants with obsessive-compulsive symptoms $(n=14)$, their mean scores were significantly higher than those of the non-OCD patients (Table 2). 
Table 2. Differences between individuals with ID and OCD and individuals with ID and without OCD concerning aberrant behaviour

\begin{tabular}{lcccc}
\hline Scale and subscale & $\begin{array}{l}\text { Whole group } \\
(n=23)\end{array}$ & $\begin{array}{c}\text { ID + OCD } \\
(n=14)\end{array}$ & $\begin{array}{c}\text { ID - OCD } \\
(n=9)\end{array}$ & $p(t$ test $)$ \\
\hline ABC Irritability & $5.7 \pm 5.2$ & $6.9 \pm 5.9$ & $3.7 \pm 3.3$ & 0.105 \\
ABC Lethargy & $5.7 \pm 7.2$ & $8.4 \pm 8.1$ & $1.4 \pm 1.6$ & $0.007^{*}$ \\
ABC Stereotypies & $2.0 \pm 2.7$ & $3.1 \pm 3.0$ & $0.3 \pm 1.0$ & $0.005^{*}$ \\
ABC Hyperactivity & $8.5 \pm 8.1$ & $11.3 \pm 8.4$ & $4.1 \pm 5.4$ & $0.021^{*}$ \\
ABC Inappropriate speech & $2.0 \pm 2.0$ & $2.6 \pm 2.2$ & $1.2 \pm 1.4$ & $0.084^{*}$ \\
ABC Total score & $23.4 \pm 19.1$ & $31.6 \pm 19.5$ & $10.6 \pm 9.2$ & $0.002^{*}$ \\
BPI Self-injurious behavior (f) & $0.3 \pm 0.8$ & $0.4 \pm 0.9$ & 0 & NS \\
BPI Self-injurious behavior (s) & $0.2 \pm 0.6$ & $0.4 \pm 0.8$ & 0 & 0.096 \\
BPI Aggressive behavior (f) & $0.7 \pm 1.1$ & $1.0 \pm 1.3$ & $0.1 \pm 0.3$ & $0.027^{*}$ \\
BPI Aggressive behavior (s) & $0.7 \pm 1.4$ & $1.1 \pm 1.7$ & $0.1 \pm 0.3$ & $0.044^{*}$ \\
BPI Stereotyped behavior (f) & $0.7 \pm 1.3$ & $1.1 \pm 1.5$ & $0.1 \pm 0.3$ & $0.022^{*}$ \\
BPI Stereotyped behavior (s) & $0.3 \pm 0.6$ & $0.5 \pm 0.8$ & $0.1 \pm 0.3$ & 0.109 \\
\hline
\end{tabular}

ABC, Aberrant Behavior Checklist [29]; BPI, Behavior Problems Inventory (Short-form) [30, 31]; $\mathrm{f}=$ frequency; $s=$ severity; NS, nonsignificant. Values as presented as mean + standard deviation; $p<0.10$, statistical tendency; ${ }^{*} p<0.05$, statistically significant.

In addition, on the BPI-S [30,31] the items "aggressive behaviour" and "stereotypies" showed the highest scores, while "self-injuring behaviour" barely featured. Again, higher scores on these items were found for the ID patients with OCD symptoms compared with those for ID patients with no OCD symptoms (Table 2).

By means of the Stereotypy Severity Scale [32], the presence of stereotypies, especially head wobbling and body rocking, was confirmed in 9 of the 23 patients. Here, number, frequency, intensity, and general impairment were all rather low. Eight of the patients with stereotypies also exhibited obsessive-compulsive symptoms. In addition, the Catatonia Rating Scale confirmed the slight manifestation of further stereotypies, such as nesting, grimacing, and mimicry.

Moreover, using the PDD-MRS, the presence of autism spectrum disorder could be identified in 3 of the 23 patients (mean PDD-MRS score: $10.5 \pm 1.3$; range: 9-12).

The overall level of emotional development (ED) evaluated by the SAED [35] was $4.8 \pm 0.3$, which is equivalent to the ED of normally developing children aged 7-12 years (reality awareness). However, no significant difference in level of ED was found between individuals with ID and OCD and those without comorbid OCD $(p=$ $0.304)$.

\section{Kinematic Characteristics}

Table 3 summarises the task-specific means and standard deviations of the kinematic parameters reflecting handwriting (sentence and letter triplets) and drawing (circle and scribble) performance for the entire sample, as well as differences between ID subjects with and without OCD.

On the basis of the standard value observed in the studies of Marquardt and Mai [39], which were performed on a normal group of practiced and experienced writers (depending on the task, the frequency $\mathrm{f}$ was between 5.5 and 4.8), our patients turned out to be twice as slow at almost every task (using frequency as the indicator of velocity).

Bradykinesia appeared most distinctly when patients were asked to write the specified sentence and draw concentric superimposed circles. Drawing a pointless scribble elicited the fastest performance from subjects.

Interestingly, patients with ID and no obsessive-compulsive symptoms tended to be noticeably slower than those with comorbid OC symptoms when writing the sentence $(p=0.080)$.

Further evidence of bradykinesia was found with patients' mean stroke duration, where the duration of every up and down stroke in comparison between task 1 (writing a given sentence) and task 11 (scribble) was, according to expectations, significantly slower (Table 3 ). 
Table 3. Kinematic characteristics

\begin{tabular}{|c|c|c|c|c|}
\hline Task variables & $\begin{array}{l}\text { Whole group } \\
(n=23)\end{array}$ & $\begin{array}{l}\text { ID + OCD } \\
(n=14)\end{array}$ & $\begin{array}{l}\text { ID - OCD } \\
(n=9)\end{array}$ & $p(t$ test $)$ \\
\hline \multicolumn{5}{|l|}{ Writing of a given sentence (T1) } \\
\hline \multicolumn{5}{|l|}{ Bradykinesia } \\
\hline Frequency, $\mathrm{Hz}$ & $2.0 \pm 1.1$ & $2.3 \pm 1.2$ & $1.6 \pm 0.6$ & $0.080^{*}$ \\
\hline Mean stroke duration, ms & $53.0 \pm 33.6$ & $49.2 \pm 30.2$ & $59.0 \pm 13.2$ & NS \\
\hline \multicolumn{5}{|l|}{ Macrographia } \\
\hline Mean stroke length, mm & $13.5 \pm 12.3$ & $8.0 \pm 3.8$ & $22.2 \pm 15.9$ & $0.028^{*}$ \\
\hline \multicolumn{5}{|l|}{ Automatization/regularity } \\
\hline Variation coefficient, \% & $76.8 \pm 7.8$ & $76.6 \pm 8.5$ & $77.1 \pm 6.9$ & NS \\
\hline NIV & $2.9 \pm 2.6$ & $2.9 \pm 2.6$ & $2.8 \pm 2.7$ & NS \\
\hline Pressure, N & $2.2 \pm 0.8$ & $2.0 \pm 0.7$ & $2.4 \pm 0.9$ & NS \\
\hline \multicolumn{5}{|l|}{ Writing of letter sequences (T2) } \\
\hline \multicolumn{5}{|l|}{ Bradykinesia } \\
\hline Frequency, $\mathrm{Hz}$ & $1.7 \pm 0.9$ & $1.8 \pm 0.9$ & $1.5 \pm 0.7$ & NS \\
\hline Mean stroke duration, ms & $255.0 \pm 223.6$ & $227.6 \pm 198.2$ & $299.2 \pm 265$ & NS \\
\hline \multicolumn{5}{|l|}{ Macrographia } \\
\hline Mean stroke length, mm & $39.0 \pm 20.4$ & $35.8 \pm 21.6$ & $44.1 \pm 18.3$ & NS \\
\hline \multicolumn{5}{|l|}{ Automatization/regularity } \\
\hline Variation coefficient, \% & $80.4 \pm 23.9$ & $80.0 \pm 24.9$ & $81.0 \pm 23.6$ & NS \\
\hline NIV & $4.0 \pm 6$ & $4.7 \pm 7.2$ & $3.1 \pm 3.8$ & NS \\
\hline Pressure, N & $1.7 \pm 0.8$ & $1.6 \pm 0.7$ & $1.7 \pm 0.9$ & NS \\
\hline \multicolumn{5}{|l|}{ Drawing of circles (T7) } \\
\hline \multicolumn{5}{|l|}{ Bradykinesia } \\
\hline Frequency, $\mathrm{Hz}$ & $1.8 \pm 0.9$ & $1.9 \pm 0.8$ & $1.7 \pm 1.0$ & NS \\
\hline Mean stroke duration, ms & $103.7 \pm 86.4$ & $101.8 \pm 75.8$ & $106.7 \pm 105.8$ & NS \\
\hline \multicolumn{5}{|l|}{ Macrographia } \\
\hline Mean stroke length, mm & $56.5 \pm 37.0$ & $40.8 \pm 20.1$ & $81.0 \pm 44.9$ & $0.030^{*}$ \\
\hline \multicolumn{5}{|l|}{ Automatization/regularity } \\
\hline Variation coefficient, \% & $87.7 \pm 11.9$ & $88.3 \pm 12.6$ & $86.7 \pm 11.4$ & NS \\
\hline NIV & $2.8 \pm 3.7$ & $2.3 \pm 2.7$ & $3.6 \pm 5.0$ & NS \\
\hline Pressure, $\mathrm{N}$ & $2.1 \pm 0.8$ & $2.1 \pm 0.8$ & $2.1 \pm 0.8$ & NS \\
\hline \multicolumn{5}{|l|}{ Scribbling (V11) } \\
\hline \multicolumn{5}{|l|}{ Bradykinesia } \\
\hline Frequency, $\mathrm{Hz}$ & $3.4 \pm 1.2$ & $3.5 \pm 1$ & $3.3 \pm 1.1$ & NS \\
\hline Mean stroke duration, ms & $393.8 \pm 236.5$ & $312.5 \pm 194.4$ & $520.2 \pm 250.1$ & 0.053 \\
\hline \multicolumn{5}{|l|}{ Macrographia } \\
\hline Mean stroke length, mm & $40.7 \pm 24.9$ & $35.1 \pm 20.7$ & $49.3 \pm 29.6$ & NS \\
\hline \multicolumn{5}{|l|}{ Automatization/regularity } \\
\hline Variation coefficient, \% & $87.4 \pm 12.6$ & $85.0 \pm 12.8$ & $91.0 \pm 12.1$ & NS \\
\hline NIV & $1.3 \pm 0.5$ & $1.5 \pm 0.6$ & $1.1 \pm 0.1$ & $0.032^{*}$ \\
\hline Pressure, $\mathrm{N}$ & $1.9 \pm 0.9$ & $2.1 \pm 0.9$ & $1.7 \pm 0.9$ & NS \\
\hline
\end{tabular}

In the writing trial (sentence), patients exhibited longer stroke lengths (in terms of larger amplitudes), which is considered an indicator of macrographia. Macrographia was particularly apparent in stroke lengths when subjects were drawing circles and drawing a pointless scribble. Interestingly, ID patients with additional OCD dis- played smaller amplitudes than those of patients with no obsessive-compulsive symptoms, while differences between the two were significant in the writing and drawing concentric circles trials (Table 3 ).

In contrast, these two groups showed no significant differences in mean vertical writing pressure, which in 
Table 4. Correlations between Y-BOCS and kinematic parameters

\begin{tabular}{llll}
\hline & Y-BOCS Obsessions & Y-BOCS Compulsions & Y-BOCS total score \\
\hline T1 stroke length, mm & $r=-0.625$ & $r=-0.455$ & $r=-0.591$ \\
& $p=0.001$ & $p=0.029$ & $p=0.003$ \\
\hline T2 stroke length, $\mathrm{mm}$ & $r=-0.519$ & $r=-0.497$ & $r=-0.508$ \\
& $p=0.011$ & $p=0.016$ & $p=0.013$ \\
\hline T7 stroke length, $\mathrm{mm}$ & $r=-0.627$ & $r=-0.481$ & $r=-0.549$ \\
& $p=0.001$ & $p=0.020$ & $p=0.007$ \\
\hline T11 stroke length, $\mathrm{mm}$ & $r=-0.260$ & $r=-0.164$ & $r=-0.206$ \\
& $\mathrm{NS}$ & $\mathrm{NS}$ & $\mathrm{NS}$ \\
\hline
\end{tabular}

comparison with experienced writers was higher but remained relatively steady over the various tasks.

Ideally, a practised script will have a unimodal velocity profile, as indicated by an NIV of 1 . The higher NIV displayed by our patients when performing the tasks demonstrates abnormal automatisation in writing and drawing. Automatisation was worst in the task of writing a letter sequence, and best in the task of drawing a pointless scribble. However, subjects with ID and OCD showed significantly worse automatisation in the scribbling task than that of subjects with ID and no OCD $(p=0.032)$.

With regard to the variation coefficient of stroke peak velocity (ideally close to 0 ), subjects' scores on all the tasks showed high values, indicating irregular velocity profiles. However, no differences were detected between the patient groups with and without additional obsessive-compulsive symptoms.

\section{Correlational Relationships}

Correlations between General Psychometrics and

Kinematic Parameters

Patients' verbal IQ scores correlated positively with frequency when writing a sentence $(r=0.691, p<0.000)$ and writing a letter sequence $(r=0.477, p=0.022)$, whereas no correlations between verbal IQ and kinematic parameters for the tasks of drawing and scribbling were found.

The extent of depressive symptoms as measured on the HAM-D had an impact only on writing a sentence: a highly significant negative correlation was found between scores on this scale and amplitude $(r=-0.695, p<0.000)$. There were no further significant correlations between any of the other kinematic parameters and depression.

Regarding general psychometrics, the highest correlations were found between mean stroke length (reflecting the amount of micrographia) and the degree of severity of OCD symptoms in all four of the test sequences (Table $4)$.

Correlations between ID-Specific Psychometrics and

Kinematic Parameters

The scales measuring abnormal behaviours of ID patients revealed correlations between stereotypies and kinematic parameters. There was a negative correlation between the handicap caused by stereotypies as measured by Severity Stereotypy Scale (SSS) and stroke lengths (amplitudes) when writing a sentence $(r=-0.493, p=0.017)$. And in task 2 (writing a letter sequence), a negative correlation between severity of stereotypies and frequency was detected $(r=-0.463, p=0.026)$.

\section{Discussion}

The main aim of our pilot study was to examine hand motor performance in individuals with ID with and without OCD, regardless of aetiology, using a digitizing graphic tablet. A secondary aim was to investigate possible associations between kinematic parameters and clinical variables in this heterogeneous population. The results of our study show that individuals with ID exhibit serious hand motor impairments suggestive of bradykinesia, irregularity, and macrographia. For writing as well as drawing with the dominant hand, we could demonstrate lower handwriting automatisation, especially in the handwriting tasks requiring greater motor control (i.e., writing a letter sequence of I's cursively). Our results are in line with the literature [e.g., 12], even though studies using a computerised digitizing graphic tablet with adult ID patients are rare. In one such study [12], a significant 
improvement in letter quality was found in 6 severely mentally retarded adults following the introduction of computerised handwriting instructions. In general, also emotional disturbances have to be taken into account in such patients with ID [41].

Going into more detail, studies of children with an autistic disorder have repeatedly shown evidence of macrographia [e.g., 42, 43]. In addition, in a study by Beversdorf et al. [44], examining the hand motor skills of adult patients with Asperger syndrome, these patients were significantly more likely to display macrographia than were those in an age- and IQ-matched control group.

Furthermore, a qualitative study using a handwriting scale with 11 adult patients with Down syndrome revealed no significant difference in writing abilities (copying sentences and their readability) compared with 11 children (corresponding to the mental development of Down sufferers) and 11 age-matched healthy controls. In the individual analyses, however, the Down patients were slower, taking $5 \mathrm{~min}$ to write 114 letters compared with 520 letters written in the same time by the age-matched healthy controls [45].

Hudson and Farran [46] found deficits in the ability to trace complex figures in people with Williams syndrome. Comparing different writing skills in people with Down syndrome or Williams syndrome, Varuzza et al. [47] found differences between the two patient groups and compared these patient groups with healthy controls with respect to false cognition error, but not for copying prescribed texts.

The studies cited here clearly indicate the presence of hand motor abnormalities in terms of writing and drawing deficits in ID patients. However, differences in methodology do not permit us to make direct comparisons. As with our investigation, other studies have used computerised digitizing graphic tablets to study specific groups. Thus, several have demonstrated the value of these devices for objectively measuring hand motor performance in healthy subjects [13] and patients with various neuropsychiatric disorders such as dementia [14], depression $[15,17]$, schizophrenia $[18,19]$, and OCD $[15,16,20,48]$.

To sum up, most of the neuropsychiatric disorders listed above entail a slowing down of writing movement; however, patients suffering from schizophrenia show a slowing down of both repetitive movements (drawing circles) and controlled writing, whereas patients with pure OCD display a loss of velocity with controlled writing but not when performing repetitive motion sequences [49]. Furthermore, patients with schizophrenia, as well as individuals suffering from dementia of the Alzheimer type, show dysfunction in automatisation and the regularity of repetitive and controlled writing movements [14, 18, 19, $50,51]$, which is comparable with the disorder profile of our patients.

By contrast, in comparison with normal controls, patients with pure OCD demonstrate abnormalities of regularity and automatisation only when performing controlled writing movements and not during repetitive movements [20]. This could not be confirmed in our study of patients with ID and additional OCD, because they had a more extensive hand movement abnormalities profile.

However, patients with ID and additional obsessivecompulsive symptoms tend to exhibit micrographia, which fits well with the results of a prior study of patients with pure OCD [20]. In our study, patients with ID and no obsessive-compulsive symptoms had significantly higher amplitudes, which would hint at macrographia, when both performing controlled writing movements and repetitively drawing circles. This result is especially interesting in light of studies of patients with Huntington's chorea, in which a tendency to macrographia has also been reported [52].

In Huntington's chorea, which involves damage to the striatum (part of the basal ganglia) resulting in hyperkinesia, comparable kinematic performance (velocity, regularity, automatisation, and amplitude) with that of our ID patients with no OCD is found. Conversely, patients with ID and obsessive-compulsive symptoms display a disorder profile comparable with patients with pure OCD.

In this context, it could be speculated that the different writing profiles are an expression of different dysfunctions of the cortico-striato-thalamocortical circuit. The different ability profiles of individuals with ID with and without obsessive-compulsive symptoms could lead to further specification of cerebral dysfunction. Therefore, replicating these results with a larger study population is clearly necessary.

The correlation of OCD symptom severity with hand motor abnormalities in our sample is of particular interest, given the association between severity of OCD symptoms and poor handwriting performance in patients with pure OCD found by Mavrogiorgou et al. [20]. In this previous study, severity of compulsions was found to be associated with less handwriting automatisation; furthermore, kinematic effects of obsessions were only found for unusual tasks, e.g. the writing of letter sequences, which is similar to the current study's findings. The effects of the severity of depression on the 
kinematic performance of persons with ID in our sample were relatively low. This too is in line with results of previous studies in which depressive patients showed little difference in comparison with healthy controls and patients with OCD $[15,17,48]$.

Interpreting the influence of stereotypies on handwriting performance is more difficult, since 8 of our ID patients with stereotypies also had obsessive-compulsive symptoms. In a future study, it would be interesting to examine the extent to which kinematic analysis is able to differentiate between stereotypies and obsessive-compulsive symptoms. Distinguishing between the two is clinically very difficult, since both are characterised by repetitive behaviours with phenotypic similarities and often comorbidly expressed in ID [53-56]. The pathophysiology of stereotypies in ID patients, as with OCD symptoms, is not well understood. However, there is growing evidence that these behaviours are associated with dysfunction in the cortical striatum-basal ganglia circuitry [57, 58]. A clear distinction between stereotypies and OCD symptoms could optimise pharmacotherapy and help to evaluate the impact of different treatments for these behaviours [59].

Writing and drawing abilities could be dependent on verbal IQ level and education level, meaning that individuals with more developed verbal intelligence and typically higher education attainment are capable of writing and drawing faster and more regularly $[13,48]$. It is also known that healthy individuals as well as patients with OCD who have high verbal intelligence and high educational attainment write faster and better than do persons with low verbal IQ scores and lower education levels [60]. The same is true in this study, in which interestingly patients with ID showed a positive correlation between verbal IQ/education level and velocity of writing (both sentence and letter sequence) but not scribbling and drawing. One possible explanation for this is a lack of cognitive abstraction ability in these for our patient's unusual tasks. However, our results can also be seen as indicating that supporting intellectual/cognitive skills has a positive effect on motor function, and on hand motion in particular, in patients with ID.

Our results revealed multidimensional hand motor abnormalities in patients with ID that are suggestive of a dysfunction of cortical striatum-basal ganglia circuits as a cerebral correlate. The different ability profiles of ID patients with and without obsessive-compulsive symptoms could lead to further specification of cerebral dysfunctions, again implying that a replication of our results with a larger study population is needed.

Handwriting in ID with and without OCD
Our study has some limitations. First, our sample was heterogeneous, and the small sample size permitted no meaningful investigation of subgroup-specific characteristics. Secondly, we did not directly compare persons with ID with healthy controls or other neurological patient groups. A third limitation is the lack of assessments of genetic aspects that could have been taken into account. Furthermore, only patients with low- and mid-level ID were examined, making it difficult to generalise our conclusions to people with severe ID. In addition, it might have been useful to utilise measures of fine motor skills, praxis (motor planning), and sensory processing. In a future study, those established measurements should be definitively included. Finally, deficits in gross motor functions (such as static balance) could have an impact on seated posture, which could then affect handwriting due to poor core strength. This potential relationship could be of high relevance, but we have not controlled for that in the current study.

Nevertheless, the findings of this pilot study are interesting and support the conduct of further studies with bigger sample sizes and subjects with more homogeneous pathophysiological and phenomenological backgrounds. Besides the issue of improvement of diagnostics, the method with the graphical tablet could also be used as a therapeutic tool; patients could train their abilities of hand movements.

\section{Acknowledgement}

The partial results presented are data for a doctoral dissertation by Oliver Schabos. We thank all patients for participation which they have done with great enthusiasm.

\section{Statement of Ethics}

All subjects gave written informed consent after the study was fully explained to them. In patients with limited legal capacity, consent was obtained from their legal representatives or caregivers after they had been given a detailed study description and explanation. In accordance with the Helsinki Declaration of 1975, the study was approved by the local university ethics committee of Ruhr University Bochum, Germany.

\section{Disclosure Statement}

None of the authors has any biomedical financial interests or potential conflicts of interest. 


\section{Funding Sources}

None.

\section{References}

1 van Bakel M, Einarsson I, Arnaud C, Craig S, Michelsen SI, Pildava S, et al. Monitoring the prevalence of severe intellectual disability in children across Europe: feasibility of a common database. Dev Med Child Neurol. 2014 Apr;56(4):361-9.

2 Fletcher R, Loschen E, Stavrakaki C, First M. Intellectual Disabilities. In: Fletcher $\mathrm{R}$, Loschen E, Stavrakaki C, First M, editors. Diagnostic Manual-Intellectual Disability (DMID); A Textbook of Diagnosis of Mental Disorders in Persons with Intellectual Disability. Kingston. NY: NADD Press; 2007.

3 Thibert RL, Larson AM, Hsieh DT, Raby AR, Thiele EA. Neurologic manifestations of Angelman syndrome. Pediatr Neurol. 2013 Apr; 48(4):271-9.

4 Lam MY, Hodges NJ, Virji-Babul N, Latash ML. Evidence for slowing as a function of index of difficulty in young adults with Down syndrome. Am J Intellect Dev Disabil. 2009 Nov;114(6):411-26.

5 Barnard-Brak L, Rojahn J, Richman DM, Chesnut SR, Wei T. Stereotyped behaviors predicting self-injurious behavior in individuals with intellectual disabilities. Res Dev Disabil. 2015 Jan;36C:419-27.

6 Lutz CK. Stereotypic behavior in nonhuman primates as a model for the human condition. ILAR J. 2014;55(2):284-96.

7 Lancioni GE, Singh NN, O'Reilly MF, Sigafoos J. An overview of behavioral strategies for reducing hand-related stereotypies of persons with severe to profound intellectual and multiple disabilities: 1995-2007. Res Dev Disabil. 2009 Jan-Feb;30(1):20-43.

8 Peña-Salazar C, Arrufat F, Santos JM, Fontanet A, González-Castro G, Más S, et al. Underdiagnosis of psychiatric disorders in people with intellectual disabilities: differences between psychiatric disorders and challenging behaviour. J Intellect Disabil. 2018 Sep: 1744629518798259.

9 Bratek A, Krysta K, Kucia K. Psychiatric comorbidity in older adults with intellectual disability. Psychiatr Danub. 2017 Sep;29(3 Suppl 3):590-3.

10 Mavrogiorgou P, Schabos O, Juckel G, Hoffmann K. Zwangssymptome bei Menschen mit intellektueller Entwicklungsstörung. Fortschr Neurol Psychiatr. 2015 Jun;83(6): 314-20.

11 Abdo WF, van de Warrenburg BP, Burn DJ, Quinn NP, Bloem BR. The clinical approach to movement disorders. Nat Rev Neurol. 2010 Jan;6(1):29-37.

\section{Author Contributions}

P.M., K.H., and G.J. designed the study. O.S., K.H., B.E., and P.M. performed the investigations. O.S., P.M., and G.J. analysed the data and wrote the first draft. All authors approved the final version.
12 Brewer N, White JM. Computerized handwriting instruction with severely mentally handicapped adults. J Intellect Disabil Res. 1994 Feb;38(Pt 1):37-44.

13 Mergl R, Tigges P, Schröter A, Möller HJ, Hegerl U. Digitized analysis of handwriting and drawing movements in healthy subjects: methods, results and perspectives. J Neurosci Methods. 1999 Aug;90(2):157-69.

14 Schröter A, Mergl R, Bürger K, Hampel H, Möller HJ, Hegerl U. Kinematic analysis of handwriting movements in patients with Alzheimer's disease, mild cognitive impairment, depression and healthy subjects. Dement Geriatr Cogn Disord. 2003;15(3):13242.

15 Mergl R, Mavrogiorgou P, Juckel G, Zaudig $M$, Hegerl U. Effects of sertraline on kinematic aspects of hand movements in patients with obsessive-compulsive disorder. Psychopharmacology (Berl). 2004 Jan;171(2):179-85.

16 Mergl R, Mavrogiorgou P, Juckel G, Zaudig $M$, Hegerl U. Can a subgroup of OCD patients with motor abnormalities and poor therapeutic response be identified? Psychopharmacology (Berl). 2005 Jun;179(4):826-37.

17 Mergl R, Pogarell O, Juckel G, Rihl J, Henkel V, Frodl T, et al. Hand-motor dysfunction in depression: characteristics and pharmacological effects. Clin EEG Neurosci. 2007 Apr; 38(2):82-8.

18 Gallucci RM, Phillips JG, Bradshaw JL, Vaddadi KS, Pantelis C. Kinematic analysis of handwriting movements in schizophrenic patients. Biol Psychiatry. 1997 Apr;41(7):830-3.

19 Caligiuri MP, Teulings HL, Dean CE, Niculescu AB, Lohr J. Handwriting movement analyses for monitoring drug-induced motor side effects in schizophrenia patients treated with risperidone. Hum Mov Sci. 2009 Oct;28(5): 633-42.

20 Mavrogiorgou P, Mergl R, Tigges P, El Husseini J, Schröter A, Juckel G, et al. Kinematic analysis of handwriting movements in patients with obsessive-compulsive disorder. J Neurol Neurosurg Psychiatry. 2001 May; 70(5):605-12.

21 Hamilton M. Development of a rating scale for primary depressive illness. Br J Soc Clin Psychol. 1967 Dec;6(4):278-96.

22 Dilling H, Freyberger HJ. Internationale Klassifikation psychischer Störungen (ICD-10). In: Dilling H, Freyberger HJ, editors. Taschenführer zur ICD-10-Klassifikation psychischer Störungen. Bern: Hans Huber Verlag; 1999/ 2001.
23 Goodman WK, Price LH, Rasmussen SA, Mazure C, Delgado P, Heninger GR, et al. The Yale-Brown Obsessive Compulsive Scale. II. Validity. Arch Gen Psychiatry. 1989a Nov; 46(11):1012-6.

24 Goodman WK, Price LH, Rasmussen SA, Mazure C, Fleischmann RL, Hill CL, et al. The Yale-Brown Obsessive Compulsive Scale. I. Development, use, and reliability. Arch Gen Psychiatry. 1989b Nov;46(11):1006-11.

25 Lehrl S. Der MWT - Ein Intelligenztest für die ärztliche Praxis. Neurol Psychiatr (Bucur). 1976; 7:488-91.

26 National Institute of Mental Health. CGI: Clinical Global Impressions. In: Guy W, Bonato RR, editors. Manual for the ECDEU Assessment Battery. Chevy Chase: National Institute of Mental Health; 1970. p. 12-1-126.

27 Morosini PL, Magliano L, Brambilla L, Ugolini S, Pioli R. Development, reliability and acceptability of a new version of the DSM-IV Social and Occupational Functioning Assessment Scale (SOFAS) to assess routine social functioning. Acta Psychiatr Scand. 2000 Apr; 101(4):323-9.

28 Juckel G, Morosini PL. The new approach: psychosocial functioning as a necessary outcome criterion for therapeutic success in schizophrenia. Curr Opin Psychiatry. 2008 Nov;21(6):630-9.

29 Aman MG, Singh NN, Stewart AW, Field CJ. Psychometric characteristics of the aberrant behavior checklist. Am J Ment Defic. 1985 Mar;89(5):492-502.

30 Rojahn J, Rowe EW, Sharber AC, Hastings R, Matson JL, Didden R, et al. The Behavior Problems Inventory-Short Form for individuals with intellectual disabilities: part I: development and provisional clinical reference data. J Intellect Disabil Res. 2012a May;56(5): 527-45.

31 Rojahn J, Rowe EW, Sharber AC, Hastings R, Matson JL, Didden R, et al. The Behavior Problems Inventory-Short Form for individuals with intellectual disabilities: part II: reliability and validity. J Intellect Disabil Res. 2012b May;56(5):546-65.

32 Miller JM, Singer HS, Bridges DD, Waranch HR. Behavioral therapy for treatment of stereotypic movements in nonautistic children. J Child Neurol. 2006 Feb;21(2):119-25.

33 Leckman JF, Riddle MA, Hardin MT, Ort SI, Swartz KL, Stevenson J, et al. The Yale Global Tic Severity Scale: initial testing of a clinicianrated scale of tic severity. J Am Acad Child Adolesc Psychiatry. 1989 Jul;28(4):566-73. 
34 Bräunig P, Krüger S, Höffler J, Shugar G, Börner I. Entwicklung, Anwendung und Reliabilität einer Katatonieskala. In: Bräunig P, editor. Motorische Störungen bei schizophrenen Psychosen. Stuttgart: Schattauer Verlag; 1999.

35 Dosen A. Psychische Störungen bei geistig behinderten Menschen. Stuttgart: Gustav Fischer Verlag; 1997.

36 Dosen A. Psychische Störungen, Verhaltensprobleme und intellektuelle Behinderung. In: Heinicke K, Seidel M, editors. Psychische Störungen, Verhaltensprobleme und intellektuelle Behinderung. Göttingen: Hogrefe Verlag; 2010.

37 Kraijer DW, Melchers P. Skala zur Erfassung von Autismusspektrum-Störungen bei Minderbegabten (SEAS-M). Frankfurt: Swets Test; 2003.

38 Mai N, Marquardt C. CS-Computergestützte Analyse der Bewegungsabläufe beim Schreiben. München: Bedienungshandbuch. MedCom; 1992.

39 Marquardt C, Mai N. A computational procedure for movement analysis in handwriting. J Neurosci Methods. 1994 Apr;52(1):39-45.

40 Hollerbach JM. An oscillation theory of handwriting. Biol Cybern. 1981;39(2):139-56.

41 Sappok T, Budczies J, Bölte S, Dziobek I, Dosen A, Diefenbacher A. Emotional development in adults with autism and intellectual disabilities: a retrospective, clinical analysis. PLoS One. 2013 Sep;8(9):e74036.

42 Fuentes CT, Mostofsky SH, Bastian AJ. Children with autism show specific handwriting impairments. Neurology. 2009 Nov;73(19): $1532-7$.

43 Johnson BP, Phillips JG, Papadopoulos N, Fielding J, Tonge B, Rinehart NJ. Understanding macrographia in children with autism spectrum disorders. Res Dev Disabil. 2013 Sep;34(9):2917-26.
44 Beversdorf DQ, Anderson JM, Manning SE, Anderson SL, Nordgren RE, Felopulos GJ, et al. Brief report: macrographia in high-functioning adults with autism spectrum disorder. J Autism Dev Disord. 2001 Feb;31(1):97-101.

45 Tsao R, Fartoukh M, Barbier ML. Handwriting in adults with Down syndrome. J Intellect Dev Disabil. 2011 Mar;36(1):20-6.

46 Hudson KD, Farran EK. Facilitating complex shape drawing in Williams syndrome and typical development. Res Dev Disabil. 2013 Jul;34(7):2133-42.

47 Varuzza C, De Rose P, Vicari S, Menghini D. Writing abilities in intellectual disabilities: a comparison between Down and Williams syndrome. Res Dev Disabil. 2015 Feb;37:13542.

48 Mavrogiorgou P, Mergl R. Husseini JEl, Juckel G, Schröter A, Rihl J., Tigges P, Zaudig M, Hegerl U. Digitized handwriting analysis in patients with obsessive-compulsive disorder. CNS Spectr. 1999;4:21.

49 Mergl R, Tigges P, Schröter A, Hegerl U. Digitalisierte Analyse der Handbewegungen im Kontext der Psychiatrie. Methodik, klinische Befunde und Perspektiven. Fortschr Neurol Psychiatr. 2000 Sep;68(9):387-97.

50 Jahn T, Cohen R, Mai N, Ehrensperger M, Marquardt C, Nitsche N, et al. Untersuchungen der fein-und grobmotorischen Dysdiadochokinese schizophrener Patienten: methodenentwicklung und erste Ergebnisse einer computergestützten Mikroanalyse. Z Klin Psychol Psychother. 1995;24:300-15.

51 Tigges P, Mergl R, Frodl T, Meisenzahl EM, Gallinat J, Schröter A, et al. Digitized analysis of abnormal hand-motor performance in schizophrenic patients. Schizophr Res. 2000 Sep;45(1-2):133-43.
52 Phillips JG, Bradshaw JL, Chiu E, Bradshaw JA. Characteristics of handwriting of patients with Huntington's disease. Mov Disord. 1994 Sep;9(5):521-30.

53 Bradley EA, Ames CS, Bolton PF. Psychiatric conditions and behavioural problems in adolescents with intellectual disabilities: correlates with autism. Can J Psychiatry. 2011 Feb; 56(2):102-9.

54 Muehlmann AM, Lewis MH. Abnormal repetitive behaviours: shared phenomenology and pathophysiology. J Intellect Disabil Res. 2012 May;56(5):427-40.

55 Chok JT, Koesler B. Distinguishing obsessivecompulsive behavior from stereotypy: a preliminary investigation. Behav Modif. 2014 May;38(3):344-73.

56 Glenn S, Cunningham C, Nananidou A, Prasher V, Glenholmes P. Routinised and compulsive-like behaviours in individuals with Down syndrome. J Intellect Disabil Res. 2015 Nov;59(11):1061-70.

57 Wood J, Ahmari SE. A framework for understanding the emerging role of corticolimbicventral striatal networks in OCD-associated repetitive behaviours. Front Syst Neurosci 2015;9:171.

58 Maltête D. Adult-onset stereotypical motor behaviors. Rev Neurol (Paris). 2016 Aug - Sep; 172(8-9):477-82.

59 Scheifes A, Egberts TC, Stolker JJ, Nijman HL, Heerdink ER. Structured medication review to improve pharmacotherapy in people with intellectual disability and behavioural problems. J Appl Res Intellect Disabil. 2016 Jul; 29(4):346-55.

60 Mergl R. Störungen der motorischen Handfunktion bei Patienten mit Zwangsstörungen [dissertation]. Munich: Munich University; 2003. 